\title{
Impact of a Health Management Program on Healthcare Outcomes among Patients on Augmentation Therapy for Alpha 1-Antitrypsin Deficiency: An Insurance Claims Analysis
}

\author{
Michael A. Campos - Michael C. Runken - Angela M. Davis • \\ Michael P. Johnson - Glenda A. Stone · Ami R. Buikema
}

Received: February 11, 2018 / Published online: April 3, 2018

(C) The Author(s) 2018

\section{ABSTRACT}

Introduction: Alpha 1-antitrypsin deficiency (AATD) is a genetic disorder which reduces

Enhanced content To view enhanced content for this article go to https://doi.org/10.6084/m9.figshare. 5962582

Electronic supplementary material The online version of this article (https://doi.org/10.1007/s12325018-0690-4) contains supplementary material, which is available to authorized users.

\section{A. Campos}

Division of Pulmonary, Allergy, Critical Care, and Sleep Medicine, University of Miami Health System, 1600 NW 10th Ave \# 7043A, Miami, FL 33136, USA

M. C. Runken

Global HEOR, Grifols Shared Services of North America, Inc., 79 T.W. Alexander Dr., 4101 Research Commons, Research Triangle Park, NC 27709, USA

\section{A. M. Davis}

Pulmonary Global Scientific and Medical Affairs, Grifols Shared Services of North America, Inc., 79 T.W. Alexander Drive, Bldg 4101, Research Triangle Park, NC 27709, USA

M. P. Johnson · A. R. Buikema ( $₫)$

Optum Life Sciences, HEOR, 11000 Optum Circle, Eden Prairie, MN 55344, USA

e-mail: ami.buikema@optum.com

G. A. Stone

Global HEOR, Medical Affairs, Grifols Shared Services of North America, Inc., 79 T.W. Alexander Dr., 4101 Research Commons, Research Triangle Park, NC 27709, USA serum alpha 1-antitrypsin (AAT or alpha1-proteinase inhibitor, A1PI) and increases the risk of chronic obstructive pulmonary disease (COPD). Management strategies include intravenous A1PI augmentation, and, in some cases, a health management program (Prolastin Direct ${ }^{\circledR}$; PD).

Objectives: This study compared clinical and economic outcomes between patients with and without PD program participation.

Methods: This retrospective study included commercial and Medicare Advantage health insurance plan members with $\geq 1$ claim with diagnosis codes for COPD and $\geq 1$ medical or pharmacy claim including A1PI (on index date). Outcomes were compared between patients receiving only Prolastin ${ }^{\circledR}$ or Prolastin ${ }^{\circledR}-\mathrm{C}$ (PD cohort) and patients who received a different brand without PD (Comparator cohort). Demographic and clinical characteristics were captured during 6 months pre-index. Post-index exacerbation episodes and healthcare utilization and costs were compared between cohorts. Results: The study sample comprised 445 patients $(n=213$ in PD cohort; $n=232$ in Comparator cohort), with a mean age 55.5 years, $50.8 \%$ male, and $78.9 \%$ commercially insured. The average follow-up was 822 days ( 2.25 years), and the average time on A1PI was 747 days (2.04 years). Few differences were observed in demographic or clinical characteristics. Adjusting for differences in patient characteristics, the rate of severe exacerbation 
episodes was reduced by $36.1 \%$ in the PD cohort. Adjusted total annual all-cause costs were $11.4 \%$ lower, and adjusted mean respiratory-related costs were $10.6 \%$ lower in the PD cohort than the Comparator cohort. Annual savings in all-cause total costs in the PD cohort relative to the Comparator cohort was US $\$ 25,529$ per patient, largely due to significantly fewer and shorter hospitalizations.

Conclusions: These results suggest that comprehensive health management services may improve both clinical and economic outcomes among patients with COPD and AATD who receive augmentation therapy.

Funding: Grifols Shared Services of North America, Inc.

Keywords: A1PI augmentation therapy; Alpha 1-antitrypsin deficiency; Alpha1-proteinase inhibitor; Chronic obstructive pulmonary disease; Disease management programs; Pulmonary; Respiratory

\section{INTRODUCTION}

Alpha 1-antitrypsin deficiency (AATD) is a genetic disorder that predisposes individuals to an increased risk of chronic obstructive pulmonary disease (COPD). AATD results from mutations in the SERPINA1 gene (also called PI), leading to a reduction in serum alpha 1-antitrypsin (AAT) levels [1]. AAT, also known as alpha1-proteinase inhibitor (A1PI), is a serine protease inhibitor that targets neutrophil elastase in the lungs. Hence, the reduced level of AAT in the lungs results in increased proteolytic activity by neutrophil elastase and other proteases [2], leading to connective tissue matrix degradation and the development of emphysema [3].

Patients with COPD associated with AATD experience a progressive decline in respiratory function, including symptoms of dyspnea and cough. These patients may also experience increased respiratory infections [4]. AATD is estimated to affect about 1 in 2000-5000 individuals [5]; however, the condition is underrecognized and diagnosis is often delayed [6]. Not all patients who are deficient for AAT develop lung disease [7], and environmental or behavioral factors (such as smoking), as well as other genetic factors, are thought to significantly influence the susceptibility to the disease [8].

General strategies for managing symptoms of AAT-deficient patients with COPD are similar to those recommended for patients with typical COPD. These include self-management, pulmonary rehabilitation programs, oxygen therapy, and the use of bronchodilators and inhaled corticosteroids [4, 9-11]. Intravenous augmentation therapy with A1PI purified from human plasma is a specific therapy for AATD approved by the U.S. Food and Drug Association. In observational studies, A1PI augmentation therapy was found to be effective at slowing decline in lung function, particularly among patients with moderate to severe obstruction [12-14], and, in randomized trials, to slow the progression of emphysema, as demonstrated by CT densitometry $[15,16]$. Additionally, augmentation therapy has been shown to reduce markers of airway inflammation and reduce the severity of acute exacerbations in patients with AATD $[16,17]$.

Prior research has examined healthcare costs in patients with AATD. Although concerns over the expense of A1PI augmentation therapy have been raised [18-21], some economic modeling studies have concluded that augmentation therapy is a cost-effective strategy for managing AATD patients with COPD [22, 23]. Furthermore, an observational study among Spanish patients showed that AATD patients with COPD experienced a significant decrease in hospitalization costs and in the incidence of exacerbations following the start of augmentation therapy [24].

Disease management programs can lead to better economic outcomes in COPD and other diseases, such as diabetes and cardiovascular disease [9, 25-28]. A fully integrated health management program called Prolastin Direct (PD) ${ }^{\circledR}$ (including education and support services provided by AlphaNet ${ }^{\circledR}$ ) has been shown to lead to improved patient reported outcomes, including improved quality of life measures, better medication use, increased use of preventive measures, and decreased healthcare resource 
utilization $[29,30]$. However, the economic impact of the PD program has not been evaluated. The objective of this study was to compare healthcare costs and resource utilization between patients receiving A1PI augmentation therapy who were enrolled in PD as compared to those who were not enrolled in the program.

\section{METHODS}

\section{Study Design and Patient Identification}

This was a retrospective study using medical claims data, pharmacy claims data, and enrollment information from two administrative health plan databases: the Optum Research Database (ORD) and the Impact National Benchmark Database (Impact). No identifiable protected health information was extracted or accessed during the course of the study. Pursuant to the Health Insurance Portability and Accountability Act, the use of de-identified data does not require Institutional Review Board approval or waiver of authorization.

The study included commercial and Medicare Advantage health plan members from the ORD and Impact databases with $\geq 1$ claim with an International Classification of Diseases, Ninth Revision, Clinical Modification (ICD-9-CM) diagnosis code for COPD (491.xx, 492.x, or 496) between January 1, 2005 and February 28, 2014 and $\geq 1$ medical or $p$ harmacy claim for A1PI [Current Procedural Terminology (CPT) codes J0256, J0257, S9346 or product-specific National Drug Codes (NDCs)] between January 1, 2008 and January 31, 2014 (patient identification period). The index date was defined at the first claim for A1PI after a patient had at least 6 months of continuous enrollment (baseline period). Patients were also required to have $\geq 1$ month of continuous enrollment post-index (follow-up period). The follow-up period ended at the earliest of health plan disenrollment or the end of study period (February 28, 2014).

For analysis, patients were divided in two groups. Using the A1PI brand as a proxy for health management program exposure, patients whose brand of infusion was Prolastin ${ }^{\circledR}$ or Prolastin ${ }^{\circledR}-C$ at index were assigned to the PD cohort and patients receiving other brands of infusion (Aralast $^{\circledR}$, Aralast-NP $^{\circledR}$, Glassia ${ }^{\circledR}$, or Zemaira ${ }^{\circledR}$ ) were assigned to the Comparator cohort (not enrolled in PD). A1PI brands were identified using a brand-specific J-code or NDC. For infusions with non-specific J-codes and no NDC code, the brand was identified if the infusions occurred at a site of service associated with a specific brand of A1PI. Patients whose brand of infusions could not be determined were excluded from the analysis.

\section{PD Program}

The services provided by the PD health management program included 2 components: disease management and treatment management. The disease management component, administered by AlphaNet ${ }^{\circledR}$, provided structured education and information about the disease, therapy, and lifestyle changes delivered via monthly calls by trained peer support coordinators who are also patients with AATD. The treatment management component coordinated medication and supply shipments, managed the insurance authorization process, and coordinated infusion therapy by an AATD patient-focused care team.

\section{Measures}

\section{Patient Characteristics}

Patient characteristics captured during baseline (i.e., 6 months pre-index) included age (as of index year), insurance type (commercial or Medicare Advantage), gender, geographic region, evidence of comorbid emphysema ( $\geq 1$ claim with ICD-9-CM diagnosis code 492.x in any position), Charlson comorbidity score [31], use of A1PI, and use of COPD maintenance and rescue medications. A1PI treatment duration was defined as the number of days between the index date and the last date for an A1PI claim during the follow-up period. COPD maintenance and rescue medication use was also assessed during follow-up.

\section{Exacerbation Episodes}

Frequency of COPD-related exacerbations, as measured by the total number of COPD-related 
exacerbation episodes during follow-up, was used as a surrogate for costs and resource utilization. Each episode could consist of multiple exacerbation events, with an episode lasting until 14 days had passed without any exacerbation events. Exacerbation events were defined as $\geq 1$ medical claim with an ICD-9-CM code for COPD-related exacerbations (490, 491.0, $491.1,491.2,491.21,491.22,491.8,491.9$, $492.0,492.8,493.12,493.22,493.92,494.1$, $466.0,496,518.81,518.82,518.84,799.1)$ in any position and classified in two mutually exclusive categories: severe and non-severe. An exacerbation was classified as severe if the event included an inpatient stay. A non-severe exacerbation was an event that included an ED visit, urgent care visit, and/or ambulatory visit coupled with a new prescription for an oral antibiotic or corticosteroid, or administration of an injectable/IV antibiotic or corticosteroid within 5 days of the visit. The numbers of severe and non-severe COPD-related exacerbation episodes during the follow-up period were reported as annual exacerbation rates.

\section{Healthcare Resource Utilization and Costs}

Healthcare resource utilization and costs were measured in the follow-up period, inclusive of the index date. Resource utilization was calculated for acute care categories, including inpatient admissions and length of inpatient stay, emergency department (ED) visits, and urgent care visits. Resource utilization for maintenance care comprised ambulatory visits (office or outpatient visits). Claims for home health service utilization were not distinguished on a per visit basis in the claims databases (i.e., a single home health service claim could represent multiple visits). Thus, the number of individual home health service visits was not quantified.

Healthcare costs were computed as the combined health plan- and patient-paid amounts for all-cause costs and respiratory-related costs. Costs were derived from claims located in any claim position. All-cause costs represented costs associated with all medical and outpatient pharmacy claims. Respiratoryrelated costs were computed as the sum of costs for: (1) all medical claims with an ICD-9-CM diagnosis code for COPD (491.xx, 492.x, or
496), COPD-related exacerbation, and AATD (273.4x); (2) A1PI treatments; (3) outpatient pharmacy claims for COPD maintenance and rescue medications; and (4) all medical and outpatient pharmacy claims for medications used in the treatment of COPD-related exacerbations (oral antibiotic or corticosteroid, administration of an injectable/intravenous antibiotic or corticosteroid). Both all-cause and respiratory-related costs were further categorized as A1PI treatment costs and non-A1PI costs (all costs exclusive of A1PI treatment costs). The cost of A1PI infusion was primarily captured in the medical cost component of non-A1PI costs. The number of A1PI infusions (and the quantity infused) could not be assessed because, similar to home health visits, multiple claims could be bundled into a single claim. Cost measures were adjusted for inflation to 2013 US dollars using the annual medical care component of the Consumer Price Index [32], and to account for costs from multiple payers. Because patients had variable follow-up durations, healthcare visits and costs were annualized.

\section{Statistical Analysis}

Between-cohort differences in patient characteristics, treatment duration, length of followup, number of COPD-related exacerbation episodes, healthcare resource utilization, and costs were assessed by $t$ test for continuous variables and Chi square test for categorical variables.

Multivariable models were used to examine differences in total all-cause healthcare costs and COPD-related exacerbation episodes during follow-up. Annualized costs were modeled using a generalized linear model with a gamma distribution and a log link [33, 34]. The total number of severe COPD-related exacerbation episodes over the follow-up period was modeled with negative binomial regression with $\log$ (years of follow-up) as an offset to account for variable follow-up time. Both models were adjusted for age category ( $<65$ years, $\geq 65$ years), gender, insurance type (commercial, Medicare Advantage), index year, geographic region, administrative claims data source (ORD, Impact), 
Charlson comorbidity score $(0,1-2,3-4, \geq 5)$, baseline evidence of emphysema and baseline use of A1PI.

In addition, sensitivity analyses were conducted among the subsets of patients with 6 and 12 months of follow-up observation time to determine if longer follow-up times would yield similar results for exacerbations and costs.

The data analysis for this paper was generated using SAS/STAT 14.2 v.9.4 software of the SAS System for Unix (2002-2012, SAS Institute, Cary, NC, USA).

\section{RESULTS}

\section{Study Sample and Patient Characteristics}

A total of 613 patients with an ICD code for COPD, treatment with A1PI during the patient identification period, and $\geq 6$ months of continuous pre-index enrollment were identified (Fig. 1). The brand of A1PI could not be determined for 164 of these patients, so they were excluded. The final study sample comprised 445 patients, with 213 patients in the PD cohort and 232 patients in the Comparator cohort. Among all patients, mean age was 55.5 years, $50.8 \%$ were male, and the majority (78.9\%) had commercial insurance (Table 1 ). The average followup duration was 822 days ( 2.25 years), and the average length of time on A1PI treatment during the follow-up period was 747 days (2.04 years). No statistically significant differences between cohorts were observed at baseline in demographic characteristics, Charlson comorbidity score, insurance type or use of A1PI, including length of follow-up time and duration of time on A1PI treatment. Similarly, no differences were observed in the mean number of claims for all COPD rescue and maintenance medications between cohorts. During baseline, the average number of COPD maintenance medication claims was 10.28 perpatient-per-year (PPPY) in the PD cohort compared with 9.57 PPPY in the Comparator cohort $(P=0.454)$ and the mean number of COPD rescue medication claims were 6.05 PPPY and 6.49 PPPY for the PD and Comparator cohorts, respectively $(P=0.569)$. Similar mean claim counts were observed during follow-up for the PD and Comparator cohorts, respectively: COPD maintenance medications, 11.28 PPPY versus 10.19 PPPY $(P=0.259)$ and COPD rescue medications, 6.46 versus $7.16(P=0.343)$.

\section{Exacerbation Episodes}

The mean PPPY number of COPD-related exacerbation episodes (severe and non-severe episodes combined) did not differ between cohorts (1.25 PD vs. 1.47 Comparator, $P=0.179$ ) (Table 2). The average number of non-severe episodes also did not differ between cohorts. However, a lower rate of severe exacerbations, defined as an episode requiring an inpatient stay, was observed in the PD cohort. The mean PPPY number of severe episodes was $47.7 \%$ lower in the PD versus Comparator cohort $(0.23$ vs. $0.44, P=0.009$ ). In multivariable analysis adjusting for differences in baseline patient characteristics between cohorts, the rate of severe exacerbation episodes during the followup period was reduced by $36.1 \%$ in the $\mathrm{PD}$ cohort (rate ratio: 0.639 ; 95\% CI: $0.424-0.964$ ) (Appendix Table A1). In addition to cohort, patient characteristics predictive of a higher rate of severe episodes included Medicare Advantage insurance (reference: commercial), Charlson score $\geq 3$ (reference 0 ), and baseline evidence of emphysema (all $P \leq 0.01$ ).

\section{Healthcare Resource Utilization and Costs}

All-cause healthcare utilization measures are shown in Table 2. Approximately one-third of all patients had an inpatient stay during followup, with $31.0 \%$ of PD patients (average duration of follow-up: 2.22 years) and $38.4 \%$ of Comparator patients (average duration of follow-up: 2.28 years) requiring inpatient care. Betweencohort differences were observed for the annualized count of inpatient stays and number of inpatient days. Patients in the PD cohort had $51 \%$ fewer PPPY inpatient stays than patients in the Comparator cohort $(0.30$ vs $0.59, P=0.012)$ and the mean number of days per inpatient stay was also considerably shorter in the PD cohort (1.96 vs. $5.49, P=0.009$ ). Ambulatory care 


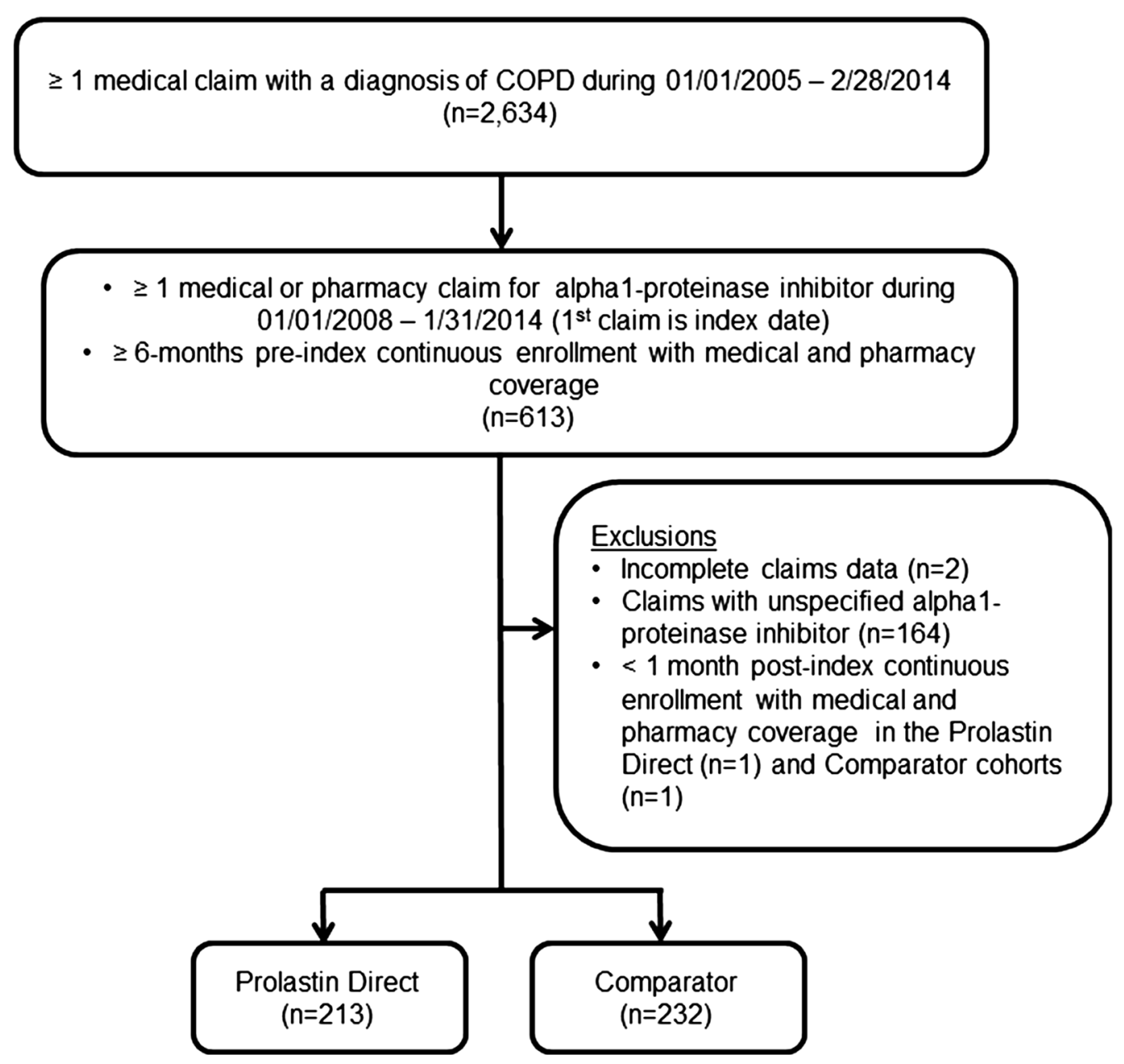

Fig. 1 Patient selection

services were extensively utilized in both cohorts with a PPPY average of 25.40 and 24.89 visits in the $\mathrm{PD}$ and Comparator cohorts, respectively $(P=0.822)$.

All-cause and respiratory-related healthcare costs, reported on a PPPY basis (due to variable length of follow-up), are shown in Table 3. Average total all-cause costs were $15.2 \%$ lower among the PD cohort versus the Comparator cohort $(\$ 142,406$ vs. $\$ 167,935, \quad P=0.010)$. Total respiratory-related costs accounted for 93\% of all-cause costs in both cohorts and were $14.7 \%$ lower in the PD cohort $(\$ 132,580$ vs. $\$ 155,341, P=0.015)$. The cost of A1PI treatment was the main driver of costs, representing $83.8 \%$ of total mean respiratory-related costs among PD patients and $79.8 \%$ of total mean respiratory-related costs among Comparator patients. All-cause costs were skewed, with 67 of 455 patients (15.1\%), accounting for $30.1 \%$ of total all-cause costs, and 10 patients (2.3\%) incurring $10.1 \%$ of total all-cause costs (Table 4). Among these 10 very high cost patients, 9 were in the Comparator cohort; after an in-depth review of these patient records, no impetus was found to remove them from analyses. After multivariable adjustment for differences in baseline and patient characteristics between cohorts, using a log-gamma model to account for skewness, adjusted total mean costs were $11.4 \%$ lower in the PD cohort [cost ratio: 0.886 ; 95\% confidence interval (CI) 0.798-0.983] with predicted mean PPPY costs of $\$ 145,458$ in the PD cohort versus $\$ 164,264$ 
Table 1 Baseline patient characteristics

\begin{tabular}{|c|c|c|c|c|}
\hline & $\begin{array}{l}\text { All patients } \\
(n=445)\end{array}$ & $\begin{array}{l}\text { PD cohort } \\
(n=213)\end{array}$ & $\begin{array}{l}\text { Comparator cohort } \\
(n=232)\end{array}$ & $P$ value $^{\text {a }}$ \\
\hline Age, years, mean (SD) & $55.5(10.1)$ & $56.3(10.1)$ & $54.8(10.1)$ & 0.136 \\
\hline \multicolumn{5}{|l|}{ Age group in years, $n(\%)$} \\
\hline $18-29$ & $3(0.7)$ & $2(0.9)$ & $1(0.4)$ & 0.513 \\
\hline $30-39$ & $21(4.7)$ & $9(4.2)$ & $12(5.2)$ & 0.638 \\
\hline $40-49$ & $102(22.9)$ & $42(19.7)$ & $60(25.9)$ & 0.123 \\
\hline $50-64$ & $236(53.0)$ & $112(52.6)$ & $124(53.5)$ & 0.855 \\
\hline $65-84$ & $80(18.0)$ & $47(22.1)$ & $33(14.2)$ & 0.031 \\
\hline$\geq 85$ & $3(0.7)$ & $1(0.5)$ & $2(0.9)$ & 0.613 \\
\hline Male, $n(\%)$ & $226(50.8)$ & $100(47.0)$ & $126(54.3)$ & 0.121 \\
\hline \multicolumn{5}{|l|}{ Geographic region, $n(\%)$} \\
\hline Northeast & $47(10.6)$ & $26(12.2)$ & $21(9.1)$ & 0.279 \\
\hline Midwest & $130(29.2)$ & $63(29.6)$ & $67(28.9)$ & 0.871 \\
\hline South & $209(47.0)$ & $94(44.1)$ & $115(49.6)$ & 0.251 \\
\hline West & $59(13.3)$ & $30(14.1)$ & $29(12.5)$ & 0.622 \\
\hline \multicolumn{5}{|l|}{ Insurance type } \\
\hline Commercial & $351(78.9)$ & $170(79.8)$ & $181(78.0)$ & 0.643 \\
\hline Medicare advantage & $94(21.1)$ & $43(20.2)$ & $51(22.0)$ & \\
\hline $\begin{array}{l}\text { Charlson comorbidity score, mean } \\
\text { (SD) }\end{array}$ & $1.3(1.0)$ & $1.3(0.9)$ & $1.4(1.0)$ & 0.326 \\
\hline \multicolumn{5}{|c|}{ Charlson comorbidity score group, $n(\%)$} \\
\hline 0 & $33(7.4)$ & $18(8.5)$ & $15(6.5)$ & 0.425 \\
\hline 1 & $326(73.3)$ & $157(73.7)$ & $169(72.8)$ & 0.837 \\
\hline 2 & $23(5.2)$ & $10(4.7)$ & $13(5.6)$ & 0.665 \\
\hline$\geq 3$ & $63(14.2)$ & $28(13.1)$ & $35(15.1)$ & 0.557 \\
\hline \multicolumn{5}{|l|}{ Conditions } \\
\hline Emphysema, $n(\%)$ & $350(78.7)$ & $176(82.6)$ & $174(75.0)$ & 0.050 \\
\hline Sleep apnea & $59(13.3)$ & $29(13.6)$ & $30(12.9)$ & 0.832 \\
\hline Congestive heart failure & $21(4.7)$ & $9(4.2)$ & $12(5.2)$ & 0.638 \\
\hline Risk smoker & $68(15.3)$ & $34(16.0)$ & $34(14.7)$ & 0.702 \\
\hline Procedures $^{b}$ & - & - & - & - \\
\hline Flu vaccine & $128(28.8)$ & $59(27.7)$ & $69(29.7)$ & 0.635 \\
\hline Nebulizer & $263(59.1)$ & $115(54.0)$ & $148(63.8)$ & 0.036 \\
\hline
\end{tabular}


Table 1 continued

\begin{tabular}{|c|c|c|c|c|}
\hline & $\begin{array}{l}\text { All patients } \\
(n=445)\end{array}$ & $\begin{array}{l}\text { PD cohort } \\
(n=213)\end{array}$ & $\begin{array}{l}\text { Comparator cohort } \\
(n=232)\end{array}$ & $P$ value $^{a}$ \\
\hline Spirometry & $264(59.3)$ & $120(56.3)$ & $144(62.1)$ & 0.219 \\
\hline Any A1PI use & $290(65.2)$ & $140(65.7)$ & $150(64.7)$ & 0.812 \\
\hline \multicolumn{5}{|l|}{ COPD maintenance medications, $n(\%)$} \\
\hline Any & $337(75.7)$ & $163(76.5)$ & $174(75.0)$ & 0.708 \\
\hline $\begin{array}{l}\text { Long-acting muscarinic antagonists } \\
\text { (LAMA) }\end{array}$ & $228(51.2)$ & $113(53.1)$ & $115(49.6)$ & 0.463 \\
\hline Inhaled corticosteroids (ICS) & $43(9.7)$ & $17(8.0)$ & $26(11.2)$ & 0.250 \\
\hline Long-acting beta-agonists (LABA) & $31(7.0)$ & $17(8.0)$ & $14(6.0)$ & 0.420 \\
\hline ICS/LABA combination & $238(53.5)$ & $116(54.5)$ & $122(52.6)$ & 0.692 \\
\hline Methylxanthines & $29(6.5)$ & $15(7.0)$ & $14(6.0)$ & 0.667 \\
\hline Phosphodiesterase-4 (PDE4) & $6(1.4)$ & $3(1.4)$ & $3(1.3)$ & 0.916 \\
\hline \multicolumn{5}{|l|}{ Inhibitors } \\
\hline Leukotriene modifiers (LM) & $90(20.2)$ & $40(18.8)$ & $50(21.6)$ & 0.467 \\
\hline \multicolumn{5}{|l|}{ COPD rescue medications, $n(\%)$} \\
\hline Any & $296(66.5)$ & $142(66.7)$ & $154(66.4)$ & 0.949 \\
\hline
\end{tabular}

in the Comparator cohort (Appendix Table A2). Adjusted mean respiratory-related costs were $10.6 \%$ lower in the PD cohort (cost ratio: $0.894 ; 95 \%$ CI $0.806-0.992$ ) with predicted mean PPPY costs of $\$ 135,672$ in the PD cohort versus $\$ 151,739$ in the Comparator cohort. For both all-cause and respiratory-related costs, patient characteristics predictive of higher costs included age $<65$ years and higher Charlson comorbidity score. For respiratory-related costs, male sex was also associated with higher costs.

Sensitivity analyses among the subsets of patients with six $(n=370)$ and 12 months $(n=300)$ of follow-up observation time produced estimates in the same direction as the main analysis; however, results from the sensitivity analyses were not statistically significant (Appendix Table A3).

\section{DISCUSSION}

These results provide evidence of the economic and clinical benefits of a comprehensive health management services program for patients with COPD and AATD receiving A1PI augmentation therapy. Patients in the PD cohort annually experienced $36.1 \%$ fewer severe exacerbation episodes requiring inpatient stays, after controlling for baseline patient characteristics.

Reductions in the frequency and severity of exacerbations reflect important clinical and economic outcomes in the management of COPD [35]. The results of this study show an important effect of a health management program in this regard. Although the nature of the data limits the ability to determine the drivers for this, it is speculated to be a reflection of actions such as personalized tailoring of 
Table 2 COPD-related exacerbations and all-cause healthcare utilization during follow-up

\begin{tabular}{|c|c|c|c|}
\hline Exacerbation episodes & PD cohort $(n=213)$ & Comparator cohort $(n=232)$ & $P$ value $^{\mathrm{a}}$ \\
\hline \multicolumn{4}{|l|}{ All episodes } \\
\hline Mean count (SD), PPPY & $1.25(1.62)$ & $1.47(1.77)$ & 0.179 \\
\hline$n(\%)^{\mathrm{b}}$ & $137(64.3)$ & $163(70.3)$ & 0.182 \\
\hline \multicolumn{4}{|l|}{ Severe episodes ${ }^{c}$} \\
\hline Mean (SD), PPPY & $0.23(0.63)$ & $0.44(1.07)$ & 0.009 \\
\hline$n(\%)^{\mathrm{b}}$ & $55(25.8)$ & $77(33.2)$ & 0.089 \\
\hline \multicolumn{4}{|c|}{ Non-severe exacerbation episodes ${ }^{\mathrm{d}}$} \\
\hline Mean (SD), PPPY & $1.02(1.46)$ & $1.02(1.34)$ & 0.991 \\
\hline$n(\%)^{\mathrm{b}}$ & $129(60.6)$ & $146(62.9)$ & 0.608 \\
\hline
\end{tabular}

\begin{tabular}{lccc}
\hline All-Cause Healthcare Resource Utilization & PD cohort $(\boldsymbol{n}=\mathbf{2 1 3})$ & Comparator cohort $(\boldsymbol{n}=232)^{P}$ value $^{\mathbf{a}}$ \\
\hline Follow-up time, mean (SD) years & $2.22(1.80)$ & $2.28(1.79)$ & 0.742 \\
Inpatient Stay & & & 0.012 \\
Mean count (SD), PPPY & $0.30(0.77)$ & $0.59(1.59)$ & 0.009 \\
Length of stay, mean days (SD) & $1.96(5.99)$ & $8.49(19.37)$ & 0.103 \\
$n(\%)^{\mathrm{f}}$ & $66(31.0)$ & $89(38.4)$ &
\end{tabular}

ER visit

Mean count (SD), PPPY

$1.15(2.76)$

$n(\%)^{\mathrm{f}}$
$1.63(5.17)$

129 (55.6)

$0.01(0.15)$

$2(0.9)$

$4(1.9)$

$25.40(21.04)$

$211(99.1)$
24.89 (26.29)

228 (98.3)
0.222

0.084

0.873

0.353

Ambulatory visit

Mean count (SD), PPPY

$n(\%)^{\mathrm{f}}$
0.822

0.473

${ }^{a} P$ value for PD cohort vs. Comparator cohort by $t$ test for continuous variables and Chi square test for categorical variables

b Number and proportion of patients with an exacerbation episode over entire duration of follow-up

c Exacerbation episodes with an inpatient stay

d Exacerbation episodes with ER visit, urgent care visit and/or ambulatory visit coupled with a new prescription for an oral antibiotic or administration of an injectable/IV antibiotic within 5 days of the visit, and no inpatient stays

e Mean counts include all patients in each cohort

${ }^{f}$ Number and proportion of patients with service category utilization over entire duration of follow-up 
Table 3 All-cause and respiratory-related healthcare costs during follow-up

\begin{tabular}{|c|c|c|c|c|c|c|}
\hline & \multicolumn{3}{|c|}{ All-cause costs, \$/PPPY } & \multicolumn{3}{|c|}{ Respiratory-related costs, \$/PPPY } \\
\hline & $\begin{array}{l}\text { PD cohort } \\
(n=213)\end{array}$ & $\begin{array}{l}\text { Comparator } \\
\text { cohort }(n=232)\end{array}$ & $P$ value $^{\mathrm{a}}$ & $\begin{array}{l}\text { PD cohort } \\
(n=213)\end{array}$ & $\begin{array}{l}\text { Comparator } \\
\text { cohort }(n=232)\end{array}$ & $P$ value $^{a}$ \\
\hline $\begin{array}{l}\text { Total costs, mean } \\
(\mathrm{SD})^{\mathrm{b}}\end{array}$ & $142,406(62,740)$ & $167,935(134,046)$ & 0.010 & $132,580(60,353)$ & $155,341(127,334)$ & 0.015 \\
\hline Medical & $113,051(79,158)$ & $138,045(142,467)$ & 0.021 & $106,409(76,999)$ & $129,555(137,773)$ & 0.028 \\
\hline $\begin{array}{l}\text { Outpatient } \\
\text { pharmacy }\end{array}$ & $29,354(47,176)$ & $29,890(48,091)$ & 0.906 & $26,171(45,716)$ & $25,786(46,424)$ & 0.930 \\
\hline $\begin{array}{l}\text { A1PI treatment } \\
\text { costs, mean }(\mathrm{SD})^{\mathrm{c}}\end{array}$ & $111,154(46,248)$ & $123,903(89,971)$ & 0.058 & $111,154(46,248)$ & $123,903(89,971)$ & 0.058 \\
\hline Medical & $88,789(63,014)$ & $101,493(101,449)$ & 0.110 & $88,789(63,014)$ & $101,493(101,449)$ & 0.110 \\
\hline $\begin{array}{l}\text { Outpatient } \\
\text { pharmacy }\end{array}$ & $22,365(44,971)$ & $22,410(46,161)$ & 0.992 & $22,365(44,971)$ & $22,410(46,161)$ & 0.992 \\
\hline $\begin{array}{l}\text { Non-A1PI costs, } \\
\text { mean }(S D)^{\mathrm{d}}\end{array}$ & $31,252(45,624)$ & $44,033(108,345)$ & 0.101 & $21,426(40,075)$ & $31,438(100,239)$ & 0.161 \\
\hline Medical & $24,263(44,209)$ & $36,553(105,553)$ & 0.105 & $17,620(39,813)$ & $28,063(100,228)$ & 0.144 \\
\hline $\begin{array}{l}\text { Outpatient } \\
\text { pharmacy }\end{array}$ & $6990(7205)$ & $7480(14,041)$ & 0.639 & $3806(3234)$ & $3376(2770)$ & 0.134 \\
\hline
\end{tabular}

augmentation therapy services along with an intense education program that improves selfmanagement, including better medication use and compliance, which likely prompts attention to seek earlier and more aggressive treatment at exacerbation onset. The frequency of severe exacerbations observed in the PD cohort (0.23 PPPY) is similar to a previous observational study (0.26 PPPY) which examined the impact of the same disease management program in patients receiving augmentation therapy [29]. However, the PD cohort was associated with a $36.1 \%$ reduction in severe exacerbations, suggesting that, even with augmentation therapy, support through a health management program may provide an opportunity to further improve patient outcomes and reduce healthcare resource utilization, thereby impacting treatment costs. It is thought that augmentation therapy does not affect the overall exacerbation rate but may ameliorate its severity [16]. Accordingly, and consistent with previous observational studies, the mean count of total exacerbations was similarly high in both cohorts in the current study [24, 36].

Further, the PD cohort had 11.4\% lower adjusted total annual costs and $10.6 \%$ lower adjusted annual respiratory-related costs in a population in which respiratory-related costs account for more than $90 \%$ of total costs. Annual savings in all-cause total costs in the PD cohort relative to the Comparator cohort were $\$ 25,529$ per patient.

The cost of A1PI treatment accounted for 78.1\% (PD cohort) and 73.8\% (Comparator cohort) of all-cause costs. A1PI treatment costs (mean cohort difference: $\$ 12,749$ ) were lower in the PD cohort but not significantly different 
Table 4 All-cause healthcare costs during follow-up by cost segment group

\begin{tabular}{|c|c|c|c|c|c|c|c|c|c|}
\hline \multirow{2}{*}{$\begin{array}{l}\text { Cost } \\
\text { group }\end{array}$} & \multirow[t]{2}{*}{$n(\%)$} & \multirow{2}{*}{$\begin{array}{l}\% \text { of total } \\
\text { costs }\end{array}$} & \multicolumn{3}{|c|}{ Total all-cause costs, \$/PPPY } & \multicolumn{2}{|c|}{ PD cohort } & \multicolumn{2}{|c|}{ Comparator cohort } \\
\hline & & & Mean & Minimum & Maximum & $n$ & $\begin{array}{l}\text { \% of cost } \\
\text { group }\end{array}$ & $n$ & $\begin{array}{l}\text { \% of Cost } \\
\text { Group }\end{array}$ \\
\hline Low & $\begin{array}{l}299 \\
(67.2)\end{array}$ & 49.8 & 115,451 & 6205 & 161,459 & 154 & 51.5 & 145 & 48.5 \\
\hline Medium & $79(17.8)$ & 20.1 & 176,321 & 161,603 & 194,000 & 29 & 36.7 & 50 & 63.3 \\
\hline High & $57(12.8)$ & 20.0 & 243,252 & 194,176 & 366,719 & 29 & 50.9 & 28 & 49.1 \\
\hline Very high & $10(2.3)$ & 10.1 & 697,871 & 387,705 & $1,341,105$ & 1 & 10.0 & 9 & 90.0 \\
\hline All & $\begin{array}{l}445 \\
\quad(100)\end{array}$ & 100 & 155,716 & 6205 & $1,341,105$ & 213 & 47.9 & 232 & 52.1 \\
\hline
\end{tabular}

${ }^{a}$ Defined as $\%$ of total costs incurred by all patients $(n=455)$ during follow-up: low, $\leq 50 \% ;>50 \%$ medium $\leq 70 \%$; $>70 \%$ high $\leq 90 \%$; very high, $>90 \%$

from the Comparator cohort. These differences may be related to differences in drug pricing, negotiated rates with the health plan, or other factors that are unobservable in claims data.

The balance of the cost savings in the PD cohort were mostly driven by the medical component of all-cause non-A1PI costs (mean cohort difference: $\$ 12,290)$. The cost savings in this category were due largely to lesser utilization of costly resources, namely significantly fewer and shorter inpatient stays in the PD cohort. The significant skewing of high costs in a small group of patients was mostly observed in the Comparator cohort, and supports the notion that the comprehensive services of a health management program are effective in managing patients, with the potential for intensive resource utilization. Also examined was the proportion of patients with exposure to A1PI during baseline as a potential confounder of follow-up costs, but no differences were found between the cohorts (65.7\% for the PD cohort and $64.7 \%$ for the Comparator cohort). In the multivariable analysis, all-cause costs were adjusted for baseline exposure to A1PI, and it was not a significant predictor of total costs. Thus, it is unlikely that differences in baseline exposure to A1PI contributed to the observed between-cohort differences in total follow-up costs.

Study results also highlight the considerable healthcare costs of AATD patients with COPD receiving augmentation therapy. Across cohorts, annual costs in 2013 US dollars averaged $\$ 155,716$ per patient. The high cost profile of patients receiving augmentation therapy is underscored by comparison with the general COPD population. The average annual all-cause costs of non-AATD patients with COPD ranged from $\$ 13,160 /$ year (2013 US dollars) among patients with no exacerbations to $\$ 20,518$ among patients with frequent exacerbations [37], or approximately $8-13 \%$ of the observed costs. High-cost conditions are an ideal target for cost-saving strategies such as services provided by a health management program.

\section{Limitations}

The results of this study should be interpreted in the context of several limitations. Claims data lack important clinical information, such as pulmonary function test results, AATD genotype/phenotype, and serum AAT levels, which could influence study outcomes. It is possible that channeling bias occurred, i.e., patients in the PD program may have fit a profile which suggested to their physician that they would benefit from comprehensive health management services, and were preferentially directed to the PD program by their physician. However, this would be more likely among patients with poorer health status which would likely attenuate, rather than increase, the 
between-cohort differences observed. It is also possible that some patients in the Comparator cohort were receiving services from AlphaNet ${ }^{\circledR}$, as it was offered by some manufacturers as an optional service during the study period. However, according to AlphaNet ${ }^{\circledR}$, more than $90 \%$ of patients enrolled in their disease management program were receiving Prolastin ${ }^{\circledR}$ or Prolastin $^{\circledR}-\mathrm{C}$ during this time (personal communication). In such a case, this would narrow, rather than expand the observed between-cohort differences. Due to the large variability in billing practices for A1PI infusion services, it was impossible to ascertain from claims data the actual infusion schedules or doses administered per infusion. Nevertheless, the lower costs of A1PI treatment in the PD cohort should not have resulted from inappropriate A1PI utilization; instead, patients in the PD program should receive more appropriate dosing. All available forms of A1PI are recommended for onceweekly infusion by body weight $(60 \mathrm{mg} / \mathrm{kg})$ [21]. Although less frequent infusion schedules have been commonly observed in clinical practice (e.g., every 2-3 weeks or monthly) $[36,38]$, the actual dose of A1PI administered over time was similar, irrespective of the infusion schedule [36]. Furthermore, although the mean follow-up time was 822 days ( 2.25 years), the minimum follow-up time required for inclusion in the study was only 1 month. Sensitivity analyses demonstrated that the power to detect differences in estimates by cohort was reduced as fewer patients had a minimum of 6 and 12 months of follow-up. Finally, the results of this study are based on patients with commercial or Medicare Advantage insurance and may not be generalizable to other populations.

\section{CONCLUSIONS}

Patients in the PD cohort had 11.4\% lower adjusted mean all-cause costs compared with patients receiving augmentation therapy from other sources. Differences in actual all-cause costs were driven by $10.6 \%$ lower adjusted respiratory-related costs in the PD cohort. The adjusted annual rate of severe exacerbations was also reduced by $36.1 \%$ among the PD cohort, although the mean number of non-severe exacerbation episodes did not differ between cohorts. These results suggest that comprehensive health management services may improve both economic and clinical outcomes among patients with COPD and diagnosed with AATD who receive augmentation therapy.

\section{ACKNOWLEDGEMENTS}

All authors participated in and contributed to study design, data interpretation, and manuscript preparation. Data collection and analysis was primarily performed by authors Buikema and Johnson. Grifols provided final corporate approval for manuscript submission. Portions of this work were presented at the following conferences: CHEST Annual Meeting 2015, Montreal, Canada; Academy of Managed Care Pharmacy Annual Meeting, 2016, San Francisco, CA; American Thoracic Society International Conference, Washington, DC; 2016.

Funding. This study was supported by Grifols Shared Services of North America, Inc., whose funding included the conduct of the study, as well as payment for medical writing services, the journal article processing charges and the journal open access fees.

Medical Writing and/or Editorial Assistance. The authors acknowledge medical writing by Sarah Pierce-Sandner and revision by Caroline Jennermann, both employed by Optum at the time of the study, as funded by Grifols.

Authorship. All named authors meet the International Committee of Medical Journal Editors (ICMJE) criteria for authorship for this article, had full access to all of the data in this study, take complete responsibility for the integrity of the data and accuracy of the data analysis, and have given their approval for this version to be published.

Disclosures. At the time of the study, Michael Campos was affiliated with the University of Miami Health System in Miami, Florida. 
Michael Runken is an employee of Grifols Shared Services of North America, Inc. Angela M. Davis is an employee of Grifols Shared Services of North America, Inc. Glenda A. Stone is an employee of Grifols Shared Services of North America, Inc. Dr. Ami R. Buikema is an employee of Optum, which was contracted by Grifols to perform the analysis; employment was not contingent upon this funding. Micheal P. Johnson is an employee of Optum, which was contracted by Grifols to perform analysis; employment was not contingent upon this funding.

Compliance with Ethics Guidelines. No identifiable protected health information was extracted or accessed during the course of the study. Pursuant to the Health Insurance Portability and Accountability Act, the use of deidentified data does not require Institutional Review Board approval or waiver of authorization.

Data Availability. The data contained in our database contains proprietary elements owned by Optum and, therefore, cannot be broadly disclosed or made publicly available at this time. The disclosure of this data to third party clients assumes certain data security and privacy protocols are in place and that the third party client has executed our standard license agreement which includes restrictive covenants governing the use of the data.

Open Access. This article is distributed under the terms of the Creative Commons Attribution-NonCommercial 4.0 International License (http://creativecommons.org/licenses/ by-nc/4.0/), which permits any noncommercial use, distribution, and reproduction in any medium, provided you give appropriate credit to the original author(s) and the source, provide a link to the Creative Commons license, and indicate if changes were made.

\section{REFERENCES}

1. Nelson DR, Teckman J, Di Bisceglie AM, Brenner DA. Diagnosis and management of patients with alpha1-antitrypsin (A1AT) deficiency. Clin Gastroenterol Hepatol. 2012;10:575-80.

2. de Serres F, Blanco I. Role of alpha-1 antitrypsin in human health and disease. J Intern Med. 2014;276:311-35.

3. Ghouse R, Chu A, Wang Y, Perlmutter DH. Mysteries of alpha1-antitrypsin deficiency: emerging therapeutic strategies for a challenging disease. Dis Models Mechanisms. 2014;7:411-9.

4. Petrache I, Hajjar J, Campos M. Safety and efficacy of alpha-1-antitrypsin augmentation therapy in the treatment of patients with alpha-1-antitrypsin deficiency. Biologics: Targets Ther. 2009;3:193-204.

5. Stoller JK, Aboussouan LS. Alpha1-antitrypsin deficiency. Lancet. 2005;365:2225-36.

6. Stoller JK, Sandhaus RA, Turino G, Dickson R, Rodgers K, Strange C. Delay in diagnosis of alpha1antitrypsin deficiency: a continuing problem. Chest. 2005;128:1989-94.

7. Tuder RM, Janciauskiene SM, Petrache I. Lung disease associated with alpha1-antitrypsin deficiency. Proc Am Thor Soc. 2010;7:381-6.

8. Foreman MG, Campos M, Celedon JC. Genes and chronic obstructive pulmonary disease. Med Clinics North Am. 2012;96:699-711.

9. Bourbeau J, Collet JP, Schwartzman K, Ducruet T, Nault D, Bradley C. Economic benefits of selfmanagement education in COPD. Chest. 2006;130:1704-11.

10. Corda L, Bertella E, La Piana GE, Boni E, Redolfi S, Tantucci C. Inhaled corticosteroids as additional treatment in alpha-1-antitrypsin-deficiency-related COPD. Respir Int Rev Thor Dis. 2008;76:61-8.

11. Donahue JM, Cassivi SD. Lung volume reduction surgery for patients with alpha-1 antitrypsin deficiency emphysema. Thorac surg Clin. 2009;19:201-8.

12. Survival and FEV1 decline in individuals with severe deficiency of alpha1-antitrypsin. The Alpha-1Antitrypsin Deficiency Registry Study Group. Am J Resp Crit Care Med 1998;158:49-59.

13. Chapman KR, Stockley RA, Dawkins C, Wilkes MM, Navickis RJ. Augmentation therapy for alpha1 antitrypsin deficiency: a meta-analysis. Chronic Obstr Pulm Dis. 2009;6:177-84.

14. Seersholm N, Wencker M, Banik N, et al. Does alpha1-antitrypsin augmentation therapy slow the annual decline in FEV1 in patients with severe hereditary alpha1-antitrypsin deficiency? 
Wissenschaftliche Arbeitsgemeinschaft zur Therapie von Lungenerkrankungen (WATL) alpha1-AT Study Group. Eur Resp J. 1997;10:2260-3.

15. Chapman KR, Burdon JG, Piitulainen E, et al. Intravenous augmentation treatment and lung density in severe alpha1 antitrypsin deficiency (RAPID): a randomised, double-blind, placebo-controlled trial. Lancet. 2015;386(9991):360-8.

16. Dirksen A, Piitulainen E, Parr DG, et al. Exploring the role of CT densitometry: a randomised study of augmentation therapy in alpha1-antitrypsin deficiency. Eur Resp J. 2009;33:1345-53.

17. Stockley RA, Bayley DL, Unsal I, Dowson LJ. The effect of augmentation therapy on bronchial inflammation in alpha1-antitrypsin deficiency. Am J Resp Crit Care Med. 2002;165:1494-8.

18. Mullins CD, Huang X, Merchant S, Stoller JK. Alpha One Foundation Research Network Registry I. The direct medical costs of alpha(1)-antitrypsin deficiency. Chest. 2001;119:745-52.

19. Mullins CD, Wang J, Stoller JK. Major components of the direct medical costs of alpha1-antitrypsin deficiency. Chest. 2003;124:826-31.

20. Gildea TR, Shermock KM, Singer ME, Stoller JK. Cost-effectiveness analysis of augmentation therapy for severe alpha1-antitrypsin deficiency. Am J Resp Crit Care Med. 2003;167:1387-92.

21. Mohanka M, Khemasuwan D, Stoller JK. A review of augmentation therapy for alpha-1 antitrypsin deficiency. Expert Op Biol Ther. 2012;12:685-700.

22. Alkins SA, O'Malley P. Should health-care systems pay for replacement therapy in patients with alpha(1)-antitrypsin deficiency? A critical review and cost-effectiveness analysis. Chest. 2000;117:875-80.

23. Sclar DA, Evans MA, Robison LM, Skaer TL. Alpha1proteinase inhibitor (human) in the treatment of hereditary emphysema secondary to alpha1-antitrypsin deficiency: number and costs of years of life gained. Clin Drug Investig. 2012;32:353-60.

24. Barros-Tizon JC, Torres ML, Blanco I, Martinez MT, Investigators of the rEXA study group. Reduction of severe exacerbations and hospitalization-derived costs in alpha-1-antitrypsin-deficient patients treated with alpha-1-antitrypsin augmentation therapy. Ther Adv Resp Dis. 2012;6:67-78.

25. Dall TM, Roary M, Yang W, et al. Health care use and costs for participants in a diabetes disease management program, United States, 2007-2008. Prev Chron Dis. 2011;8:A53.
26. Dewan NA, Rice KL, Caldwell M, Hilleman DE. Economic evaluation of a disease management program for chronic obstructive pulmonary disease. Chronic Obstr Pulm Dis. 2011;8:153-9.

27. Sidorov J. Reduced health care costs associated with disease management for chronic heart failure: a study using three methods to examine the financial impact of a heart failure disease management program among medicare advantage enrollees. J Cardiac Failure. 2006;12:594-600.

28. Boland MR, Tsiachristas A, Kruis AL, Chavannes NH, Rutten-van Molken MP. The health economic impact of disease management programs for COPD: a systematic literature review and meta-analysis. BMC Pulmonary Med. 2013;13:40.

29. Campos MA, Alazemi S, Zhang G, Wanner A, Sandhaus RA. Effects of a disease management program in individuals with alpha-1 antitrypsin deficiency. Chronic Obstr Pulm Dis. 2009;6:31-40.

30. Perkins JT, Choate R, Mannino DM, Browning SR, Sandhaus RA. Benefits among patients with alpha-1 antitrypsin deficiency enrolled in a disease management and prevention program. Chronic Obstr Pulm Dis. 2016;4(1):56-64.

31. Quan H, Li B, Couris CM, et al. Updating and validating the Charlson comorbidity index and score for risk adjustment in hospital discharge abstracts using data from 6 countries. Am J Epidemiol. 2011;173:676-82.

32. United States Department of Labor Bureau of Labor Statistics. Consumer Price Index. Chained Consumer Price Index for all urban consumers (C-CPIU) 1999-2013, Medical Care. 2014. Available at http://connection.ebscohost.com/c/articles/876639 79/table-1c-chained-consumer-price-index-all-urbanconsumers-c-cpi-u-u-s-city-average-by-expenditurecategory-commodity-service-group. Accessed 14 March 2017.

33. Manning WG. The logged dependent variable, heteroscedasticity, and the retransformation problem. J Health Econ. 1998;17:283-95.

34. Manning WG, Mullahy J. Estimating log models: to transform or not to transform? J Health Econ. 2001;20:461-94.

35. Teschler H. Long-term experience in the treatment of alpha1-antitrypsin deficiency: 25 years of augmentation therapy. Eur Resp Rev: Offic J Eur Resp Soc. $2015 ; 24: 46-51$.

36. Campos MA, Alazemi S, Zhang G, et al. Exacerbations in subjects with alpha-1 antitrypsin deficiency receiving augmentation therapy. Resp Med. 2009;103:1532-9. 
37. Dalal AA, Patel J, D'Souza A, Farrelly E, Nagar S, Shah M. Impact of COPD exacerbation frequency on costs for a managed care population. J Manag Care Spec Pharm. 2015;21:575-83.
38. Stoller JK, Fallat R, Schluchter MD, et al. Augmentation therapy with alpha1-antitrypsin: patterns of use and adverse events. Chest. 2003;123:1425-34. 